\title{
FLAP DE TERCEIRA PÁLPEBRA PARA TRATAMENTO DE ÚLCERA DE CÓRNEA COLAGENOLÍTICA DIFUSA EM CÃO: RELATO DE CASO
}

Ana Paula de Souza Martins da Silva ${ }^{1}$, Patrícia Rosa de Assis ${ }^{2}$, Fernando Antônio Bretas Viana ${ }^{3}$, Andréia Vitor Couto do Amaral ${ }^{4}$

${ }^{1}$ Médica Veterinária, Residente do Programa de Residência Multiprofissional na Área de Clínica, Cirurgia e Anestesiologia de Animais de Companhia, Regional Jataí,

Universidade Federal de Goiás, Jataí, Brasil. paulamaturaca@hotmail.com

${ }^{2}$ Médica Veterinária, Técnica Administrativa do Hospital Veterinário, Regional Jataí,Goiás, Brasil.

${ }^{3}$ Médico Veterinário, Professor Adjunto da Escola de Medicina Veterinária da UFMG, Belo Horizonte, MG, Brasil.

${ }^{4}$ Médica Veterinária, Prof. - Adjunta do curso de Medicina Veterinária, Regional Jataí, Universidade Federal de Goiás, Jataí, Brasil.

Recebido em: 08/09/2015 - Aprovado em: 14/11/2015 - Publicado em: 01/12/2015 DOI: http://dx.doi.org/10.18677/Enciclopedia_Biosfera_2015_160

\begin{abstract}
RESUMO
As úlceras colagenolíticas, também chamadas úlceras em Melting, úlceras de liquefação, ou ainda ceratomalácia, constituem uma alteração grave da córnea, com necessidade de intervenção rápida e agressiva, com alto risco de perda permanente da visão ou ruptura do globo ocular. São resultantes de uma destruição progressiva do estroma corneal, acarretando em fragmentação do colágeno, com liquefação e necrose da córnea. O presente estudo de caso relata a úlcera de córnea colagenolítica difusa em cão da raça Shih Tzu, a qual teve como tratamento cirúrgico o recobrimento corneal com flap simples de terceira pálpebra, com fixação palpebral, além da utilização de antibióticos, cicloplégicos e inibidor de proteases tópicos. Mesmo este não sendo a técnica cirúrgica de eleição preconizada na literatura, alcançou o sucesso terapêutico devido à progressiva recuperação da visão do paciente.
\end{abstract}

PALAVRAS-CHAVE: afecção oftálmica, ceratomalácia, emergência oftálmica.

\section{THIRD EYELID FLAP FOR TREATMENT OF DIFFUSE CORNEAL ULCER MELTING IN A DOG: CASE REPORT}

\begin{abstract}
The collagenolytic ulcers, ulcers Melting also called, liquefaction ulcers, or Keratomalacia constitute a serious deterioration of the cornea, with the need for rapid and aggressive intervention with high risk of permanent vision loss or breakage of the eyeball. It results from a progressive destruction of the corneal stroma, resulting in collagen fragmentation, with liquefaction and necrosis of the cornea. This case study relates the diffuse corneal ulcer melting in breed dog Shih Tzu, which had the surgery the corneal coating with simple flap third eyelid with eyelid fixing, besides the use of antibiotics, cycloplegic and topical inhibitor of proteases. Even this not being
\end{abstract}


the surgical technique of choice recommended in the literature, achieved therapeutic success due to the gradual recovery of the patient's vision.

KEYWORDS: ophthalmic disease, ophthalmic emergency, Keratomalacia.

\section{INTRODUÇÃO}

Úlceras de córnea constituem um problema frequente na clínica de animais de companhia (GELATT \& BROOKS, 2011a). Como complicação destas úlceras, pode ocorrer um desequilíbrio entre a ação das proteinases endógenas do estroma corneal e os fatores inibidores de proteinases, levando a uma intensa degradação do colágeno (OLLIVIER et al., 2007). Assim, as úlceras colagenolíticas, também chamadas úlceras em Melting, úlceras de liquefação, ou ainda ceratomalácia, são resultantes de uma destruição progressiva do estroma corneal, acarretando em fragmentação do colágeno, com liquefação e necrose da córnea (GALERA et al., 2009; TURNER, 2010, DUBIELZIG et al, 2010). Constituem uma alteração grave da córnea, com necessidade de intervenção rápida e agressiva, com alto risco de perda permanente da visão ou ruptura do globo ocular (GILGER et al., 2013; MAGGS, 2013).

Além de ser produto da ação de proteinases endógenas, a úlcera colagenolítica também pode ser causada pela presença de microrganismos infecciosos, tais como Pseudomonas sp. e, mais raramente, fungos colonizadores oportunistas, que levam à degradação do colágeno estromal (GALERA et al., 2009; TURNER, 2010; MAGGS, 2013; POT et al., 2014). Também foi relatado como causa de colagenólise corneal, o leite de mamão, que é um álcali, que entrou em contato com os olhos de um cão, relatado por GALERA et al., (2004).

Algumas raças foram apontadas como mais predispostas às úlceras colagenolíticas, dentre as quais aquelas braquicefálicas. Entretanto, podem ocorrer em qualquer raça ou idade (OLLIVIER et al., 2007; GALERA et al., 2009; MAGGS, 2013; POT et al., 2014). Segundo MAGGS (2013), os fatores que possibilitam ulcerações corneanas, e subsequentemente, o desencadeamento do processo de liquefação da córnea nos cães são os traumatismos, os corpos estranhos, a distiquíase, a ceratite seca, o entrópio, a erosão superficial da córnea, o edema crônico da córnea e as neoplasias da margem palpebral. KIM et al. (2009), VONGSAKUL et al. (2009), BRITO et al. (2010) e CAMPOS et al. (2003), complementam essa lista com a exposição a materiais nocivos, os problemas congênitos ou iatrogênicos e a deficiência na produção lacrimal de qualquer natureza.

O diagnóstico é feito com base no histórico, anamnese e no exame físico, que, como citado por TURNER (2010), a úlcera colagenolítica estará bem evidente, por apresentar uma aparência gelatinosa, de coloração normalmente que varia do bege ao acinzentado, com intensa opacidade corneal. No histórico é comum o relato de evolução muito rápida e agressiva.

Para o tratamento, de forma geral, são indicados antimicrobianos tópicos, inibidores de protenases e cicloplégicos tópicos (GALERA et al., 2009). As intervenções cirúrgicas devem ocorrer, segundo TURNER (2010), quando existe o risco de ruptura da córnea. Entretanto, geralmente é realizado tratamento tópico intensivo por um período de 24 a 48 horas antes do procedimento cirúrgico, para estabilização do quadro, como diminuição da aparência gelatinosa ou da profundidade da úlcera. Porém, se for notada uma piora do quadro, a cirurgia deverá ser indicada imediatamente. GALERA et al., (2009) afirmaram que os flaps 
conjuntivais e os enxertos pediculados são os mais frequentemente utilizados, sendo possível a realização dos flaps de terceira pálpebra em situações emergenciais. PUMPHREY et al., (2011) usaram o enxerto conjuntival $360^{\circ}$ para o tratamento de úlcera colagenolítica em cão.

Foram também verificados na literatura a utilização de enxertos utilizando membranas biológicas na reconstrução da córnea de cães ou gatos com ulcerações, dentre as quais a colagenolítica, como o de submucosa de bexiga urinária suína (ACellVet®) (CHOW \& WESTERMEYER, 2015), de pericárdio bovino (Tutopatch®) (DULAURENT et al., 2014), de submucosa de intestino delgado (Vet Biosist $\AA$ ) (GOULLE, 2012) e de membrana amniótica (PONTES et al., 2011). Também foi relatado o tratamento por crosslinking corneal por alguns autores (FAMOSE, 2014; POT et al., 2014; SPIESS et al., 2014).

O presente relato descreve um caso clínico de úlcera de córnea colagenolítica em um cão, atendido no Hospital Veterinário da Universidade Federal de Goiás, Regional Jataí, onde se utilizou com sucesso o flap simples de terceira pálpebra no tratamento.

\section{DESCRIÇÃO DO CASO}

Foi atendido, no Serviço de Oftalmologia Veterinária do Hospital Veterinário da Universidade Federal de Goiás, Regional Jataí, Jataí, Goiás, um cão da raça Shih Tzu, macho, de aproximadamente um ano de idade e 4,1 Kg de peso corporal, com a queixa principal de olho esquerdo opaco e com secreção.

$\mathrm{Na}$ anamnese, foi informado pelo tutor que há dois dias notou o olho esquerdo opaco com lacrimejamento, com agravamento do quadro desde então. Para o exame oftalmológico foram utilizados biomicroscópio com lâmpada de fenda (SL-14 Kowa, Japão), tonometria de aplanação (Tonopen XL, Mentor), oftalmoscopia direta (Heine, Alemanha) e indireta (IO-H, Neitz) e tiras de fluoresceína sódica (Fluoresceína Strips, Ophthalmos, SP, Brasil). No olho esquerdo (Figura 1A), notouse opacidade de córnea acentuada, com edema difuso e aparência gelatinosa, secreção seromucosa em grande quantidade, hiperemia episcleral intensa e blefaroespasmo. Não foi possível a visibilização da câmara anterior e do segmento posterior oculares por oftalmoscopia direta ou indireta, devido à intensa opacidade em toda a extensão da córnea. Entretanto, notou-se a presença do reflexo fotopupilar consensual. O exame do olho direito não evidenciou alterações. A pressão intraocular do olho esquerdo foi de $19 \mathrm{mmHg}$ e do olho direito $22 \mathrm{mmHg}$, aferidas após a instilação de colírio de proximetacaína a 0,5\% (Anestalcon®). A prova de tingimento pela fluoresceína mostrou-se positiva no olho esquerdo.

Ao exame clínico geral foi observado que todos os parâmetros fisiológicos

estavam dentro da normalidade. Procedeu-se a coleta de sangue total para realização de hemograma com pesquisa de hematozoários e bioquímica sérica (creatinina, uréia, fosfatase alcalina e alanina transferase), os quais se apresentaram sem alterações significativas.

Imediatamente, iniciou-se a terapêutica com colírio de tobramicina a $0,3 \%$, uma gota a cada um minuto por cinco minutos no olho esquerdo, seguidas de uma gota a cada duas horas, nas dependências do setor de internação do Hospital Veterinário da Regional Jataí. Foram prescritos também uma gota de colírio de atropina a $0,5 \%$ a cada 24 horas e uma gota de colírio de EDTA a $2 \%$ a cada oito horas no olho esquerdo. Decorridas quatro horas, optou-se pela cirurgia de flap simples de terceira pálpebra. 
No pré-operatório imediato iniciou-se fluidoterapia para manutenção do acesso venoso com solução de Cloreto de Sódio $(\mathrm{NaCl})$ a $0,9 \%$, na dose de 5 $\mathrm{ml} / \mathrm{kg} / \mathrm{hora}$. Para a medicação pré-anestésica (MPA) utilizou-se morfina na dose de $0,3 \mathrm{mg} / \mathrm{Kg}$ (IM) e Midazolan na dose de 0,2 $\mathrm{mg} / \mathrm{kg}$ (IM). A indução anestésica foi procedida com propofol na dose de $3 \mathrm{mg} / \mathrm{kg}$ (IV) em "bolus", seguida da intubação oro-traqueal com sonda traqueal n\%. A manutenção a nestésica se deu pela utilização de isofluorano.

O paciente foi posicionado em decúbito lateral direito e procedeu-se a tricotomia peri-ocular e antissepsia. O olho foi lavado com aproximadamente $100 \mathrm{~mL}$ de solução preparada com $500 \mathrm{~mL}$ de solução fisiológica de cloreto de sódio a $0,9 \%$ e $5 \mathrm{~mL}$ de solução tópica de iodopovidona a 10 \% (PVPI). Então foram posicionados os panos de campo.

Assim que o paciente atingiu o plano anestésico adequado, o procedimento cirúrgico foi iniciado, utilizando a técnica de flap de terceira pálpebra com fixação palpebral, segundo descrito por TUDURY \& POTIER (2009), onde a pálpebra superior é levantada da superfície ocular e transfixada primeiramente pela parte externa para a interna, com fio de náilon agulhado 5-0, a aproximadamente $5 \mathrm{~mm}$ da borda, na parte medial. Logo, a borda da terceira pálpebra foi pinçada e também transfixada, sendo acomodada sob a pálpebra superior que é novamente transfixada, agora de dentro para fora, e o ponto é fixado pela parte externa da pálpebra, para que o nó não fique em contato com a superfície ocular, finalizando o ponto cirúrgico tipo "colchoeiro". Foram efetuados três pontos equidistantes, para correta fixação cranial da terceira pálpebra sob a pálpebra superior (Figura 1B).
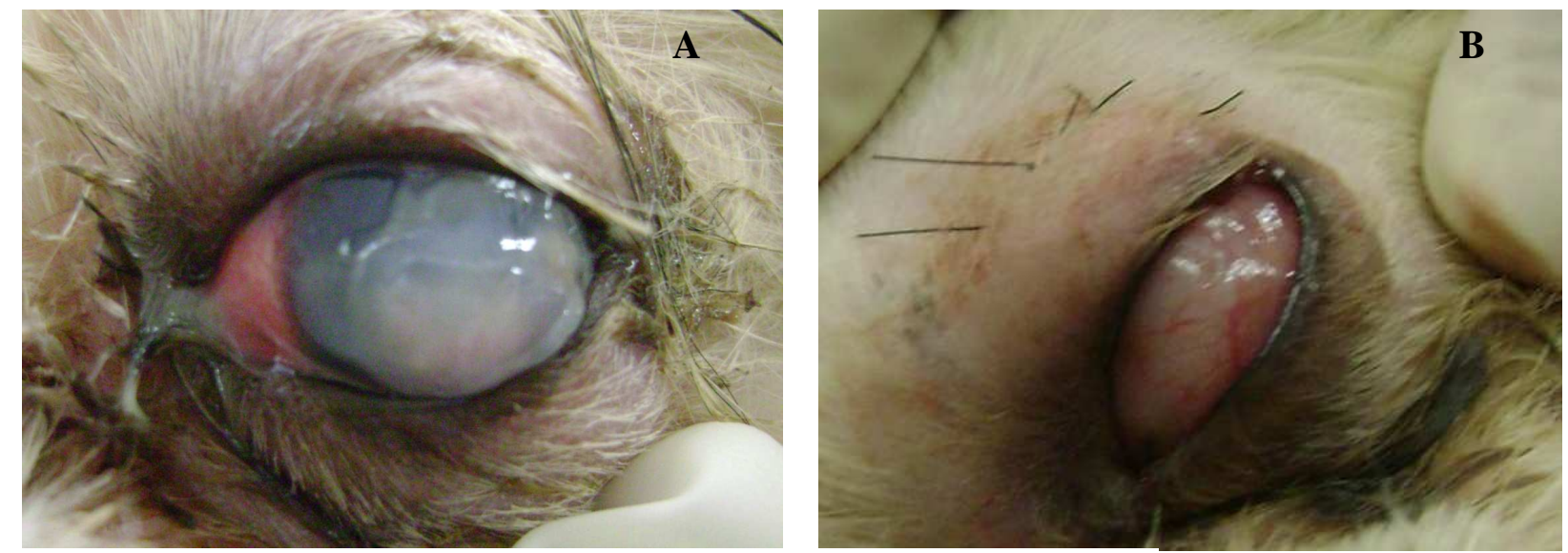

FIGURA 1 - Olho esquerdo de cão da raça Shih Tzu. A) Opacidade de córnea acentuada, com edema difuso e aparência gelatinosa. B) Resultado pós cirúrgico evidenciando o Flap simples de terceira pálpebra.

O protocolo terapêutico pós-cirúrgico imediato sistêmico constou de analgesia com cloridrato de tramadol na dose de $2 \mathrm{mg} / \mathrm{Kg}$ (IM) e dipirona sódica na dose de $25 \mathrm{mg} / \mathrm{Kg}(\mathrm{IM})$, meloxicam na dose de $0,2 \mathrm{mg} / \mathrm{Kg}$ (IM) e antibioticoterapia com ceftriaxona na dose de $30 \mathrm{mg} / \mathrm{Kg}(\mathrm{IM})$.

O animal foi então observado até completo reestabelecimento dos parâmetros fisiológicos pós-cirúrgicos e a alta ocorreu no mesmo dia, com estritas recomendações de uso contínuo do colar elisabetano. Foram prescritos cefalexina na dose de $30 \mathrm{mg} / \mathrm{Kg}$ por via oral, a cada 12 horas, por 10 dias; meloxicam na dose de $0,1 \mathrm{mg} / \mathrm{Kg}$ por via oral, a cada 24 horas, por três dias e dipirona sódica na dose de $25 \mathrm{mg} / \mathrm{kg}$, por via oral, a cada oito horas, por três dias. Para terapia tópica ocular foi 
prescrito o colírio a base de moxifloxacino a 0,5\% (Vigamox®), uma gota, a cada quatro horas, no olho esquerdo, a ser instilado diretamente na face palpebral da terceira pálpebra, por 15 dias, em substituição ao colírio de tobramicina a 0,3\%. Foi recomendada a continuidade do colírio de atropina e do colírio de EDTA por mais cinco dias, conforme prescrição do pré-operatório. Os pontos do flap seriam mantidos por 21 dias.

\section{RESULTADOS E DISCUSSÃO}

O diagnóstico foi dado considerando-se o histórico, a anamnese e o exame específico, onde as alterações clínicas oftálmicas indicaram prontamente que se tratava de uma úlcera de córnea do tipo colagenolítica, conforme descrito por OLLIVIER et al. (2007), GALERA et al., (2009), TURNER (2010), MAGGS (2013), POT et al.(2014), sendo que, o aspecto gelatinoso da lesão foi preponderante para tal afirmação.

Apesar da gravidade da lesão corneal e à impossibilidade de fundoscopia pela acentuada opacidade de córnea, o potencial da visão do paciente pode ser verificado pela presença do reflexo fotopupilar consensual (CHOW \& WESTERMEYER, 2015). É importante lembrar que a ultrassonografia ocular seria um bom instrumento diagnóstico para avaliação anatômica das estruturas intraoculares, entretanto, pelo risco de ruptura da córnea, optou-se por não fazê-la (KEALY \& McALLISTER, 2005). A pressão intraocular encontrava-se dentro dos limites considerados normais na literatura (MARTINS et al., 2009).

A instituição do tratamento de forma rápida e agressiva, instilando uma gota de colírio a base de tobramicina a $0,3 \%$, com subsequentes repetições a cada duas horas foi procedida conforme indicaram HERRERA (2008) e VIANA et al. (2011). Colírios inibidores de protease são fundamentais para o tratamento, sendo que, o colírio de EDTA, indicado no relato em questão, é o mais efetivo (GALERA et al., 2009). O colírio de atropina a $0,5 \%$ foi prescrito como referido na literatura consultada (HERRERA, 2008; GALERA et al., 2009; VIANA et al., 2011). Trata-se de ciclopégico, que age promovendo paralisia no corpo ciliar, diminuindo a dor intraocular causada pelo espasmo do corpo ciliar em casos de úlceras. Também diminui a possibilidade de aderências da íris (sinéquias), ao diminuir a superfície de contato pela midríase gerada (VIANA et al., 2011; MILLER, 2013). Prontamente foi indicado o tratamento cirúrgico pela gravidade do quadro clínico ocular, o que tornou a córnea extremamente susceptível ao rompimento, com possibilidade de perda da anatomia funcional do globo ocular e subsequente consequente perda permanente da visão (GILGER et al., 2013; MAGGS, 2013).

Considerando-se que o flap de terceira pálpebra oferece uma barreira de proteção mecânica à córnea, este foi escolhido ao invés dos flaps conjuntivais ou enxertos. Justifica-se também pela facilidade na execução, pelo menor tempo de anestesia geral a que o animal é exposto. De forma semelhante ao que ocorre aos flaps conjuntivais, no flap de terceira pálpebra é possível a continuidade do tratamento tópico com colírios, com a vantagem de promover um maior tempo de contato do fármaco com a superfície ocular. Além disso, sabe-se que os flaps conjuntivais se aderem ao estroma corneano em toda a extensão da área ulcerada por longos períodos (GELATT \& BROOKS, 2011a). Como no paciente em questão praticamente toda a área da córnea estava acometida, haveria uma grande aderência de conjuntiva e consequente demora ao restabelecimento da função visual. 
O procedimento cirúrgico adotado está de acordo com o descrito por SAMPAIO (2007), que recomenda o recobrimento com terceira pálpebra como uma das opções cirúrgicas existentes, pois BOJRAB (1996) afirma que a terceira pálpebra, por ser bem desenvolvida nos animais, fornece uma boa proteção para 0 globo, e mais precisamente para a córnea. Segundo GALERA et al., (2009), os flaps de terceira pálpebra excepcionalmente podem ser empregados, ainda que menos vantajosos que os enxertos conjuntivais.

Para o pós-cirúrgico, optou-se pela prescrição do moxifloxacino como antimicrobiano tópico por apresentar largo espectro de ação e menor resistência bacteriana quando comparado à tobramicina (VIANA et al., 2011). A escolha foi influenciada pela ausência de cultura e antibiograma tal como recomendado por POT et al. (2014) e pela possibilidade da colagenólise ser causada por agentes bacterianos, a exemplo de Pseudomonas sp. (GALERA et al., 2009; TURNER, 2010; MAGGS, 2013; POT et al., 2014).

A remoção dos pontos cirúrgicos ocorreu no $21^{\circ}$ dia após o procedimento cirúrgico, conforme indicado por GELATT \& BROOKS (2011b). Não houve deiscência do flap de terceira pálpebra realizado, mostrando uma boa evolução pósoperatória no caso relatado. Já os flaps conjuntivais e enxertos estão relacionados com deiscência, em taxas variadas, em casos de colagenólise. CHOW \& WESTERMEYER (2015) avaliaram a viabilidade do enxerto de submucosa de bexiga urinária suína para a reconstrução de defeitos corneais profundos, dentre os quais casos de úlceras colagenolíticas e obtiveram uma taxa de deiscência do enxerto maior quando comparada às técnicas convencionais em cães.

$\mathrm{Na}$ ocasião da remoção dos pontos, o paciente apresentava discreta secreção ocular seromucosa no olho em questão. Com a remoção dos pontos, verificou-se que a cicatrização da córnea ocorreu conforme o esperado, apresentando tecido de cicatrização na área central, com neovascularização e opacidade moderada (Figura 2A). Com a biomicroscopia em lâmpada de fenda pôde-se observar a integridade da íris em sua periferia. A resposta à ameaça do olho esquerdo foi positiva, o que indicou a capacidade visual do mesmo. Entretanto, ainda havia moderada hiperemia episcleral, que, em conjunto à secreção observada, optou-se pela continuidade da antibioticoterapia tópica de forma vigorosa. Assim o colírio a base de moxifloxacino a $0,5 \%$ (Vigamox®) foi prescrito para instilações a cada duas horas, por 48 horas, seguidos por administração a cada seis horas por mais sete dias. Foi acrescentado o colírio a base de sulfato de condroitina "A" a $20 \%$ (Tears $\AA$ ), duas gotas, quatro vezes ao dia, por 21 dias, com finalidade lacrimomética e lubrificante da superfície ocular (VIANA et al., 2011).

O retorno subsequente, três semanas após a remoção dos pontos cirúrgicos, foi observado uma melhora da aparência da córnea, com diminuição da opacidade e do tecido cicatricial (Figura 2B). Assim a recomendação foi de utilização constante de colírios para lubrificação ocular, que pode ser feita com duas gotas de solução oftálmica de dextrana e hipromelose (Lacrima plus®), que contêm agentes umectantes capazes de prolongar o contato da córnea com a conjuntiva que a circunda e promovem maior viscosidade do filme, para melhor lubrificação da superfície ocular (HERRERA, 2008). 

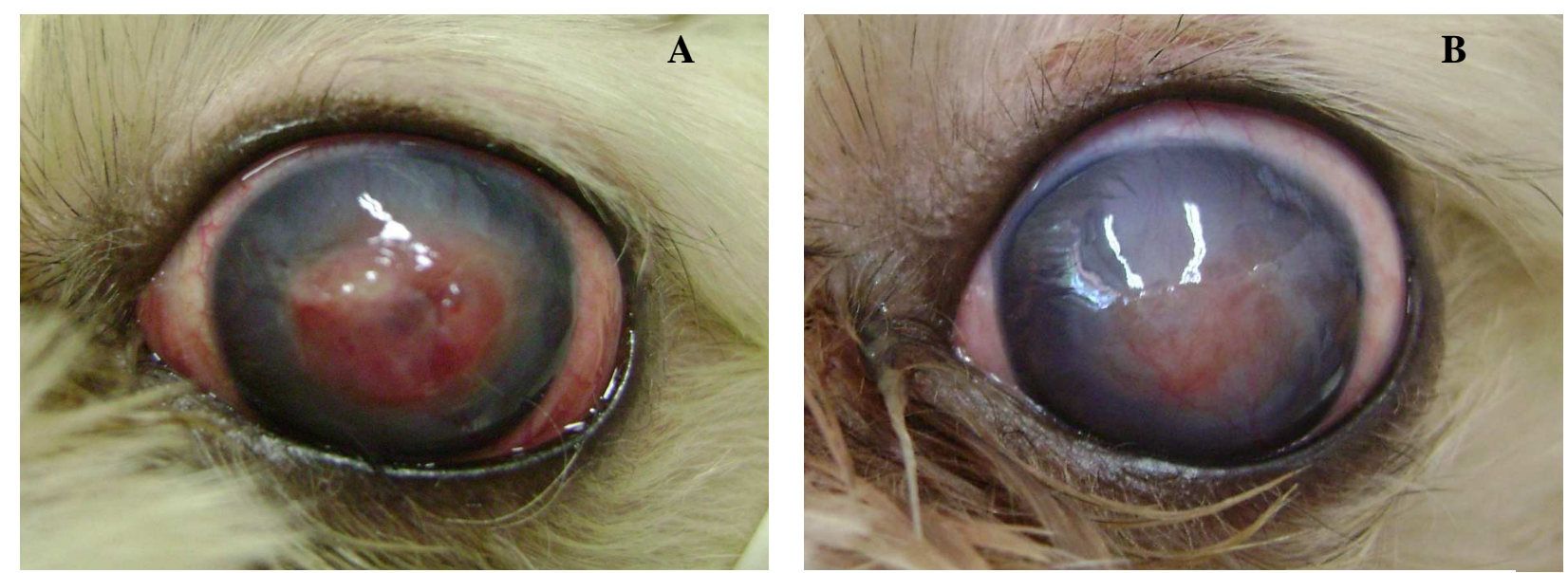

FIGURA 2 - Olho esquerdo de cão da raça Shih Tzu. A) 21 dias após a realização do flap de $3^{\mathrm{a}}$ pálpebra: tecido de cicatrização na área central da córnea e neovascularização, opacidade de córnea e hiperemia episcleral. B) 42 dias após a realização do flap de $3^{a}$ pálpebra: diminuição da opacidade de córnea e da hiperemia episcleral.

A transparência da córnea é dependente de uma perfeita disposição do colágeno em lamelas estromais. Proteoglicanos e outros componentes da substância basal, mantêm a posição apropriada das fibrilas. Durante o acompanhamento da recuperação do olho do paciente, nota-se uma opacidade acentuada devido a um desarranjo na deposição das fibras colágenas, as quais não se depositam em filas paralelas, causado pelo processo cicatricial em lesões estromais profundas (GALERA et al., 2009). Entretanto, com o decorrer do período de avaliação, pôde-se observar uma melhora da opacidade da córnea e diminuição do tecido de cicatrização na área central.

Observou-se na literatura consultada, uma busca de tratamento para úlcera de córnea que buscam não só a cicatrização e manutenção da camada fibrosa ocular, mas também o retorno da transparência da córnea. Assim, método utilizando o crosslinking também surge como alternativa aos enxertos e flaps, mas apresentam resultados promissores (POT et al., 2014; SPIESS et al., 2014). A técnica utiliza instilações oftálmicas de solução de riboflavina a $0,1 \%$ e de dextrano a $20 \%$ seguidas da exposição da córnea a luz UVA com aparelho específico. O método já é utilizado na rotina em seres humanos e não exclui a utilização de colírios antibióticos e cicloplégicos como nos tratamentos convencionais de úlcera de córnea colagenolítica, mas evita o procedimento cirúrgico e aumenta a força biomecânica do colágeno e diminui a degradação de enzimas proteolíticas (ESCARIÃO et al., 2013). Entretanto, ainda não está disponível na rotina da medicina veterinária.

Diante de todos esses fatos, destaca-se, portanto, a importância da escolha da técnica que seja adequada ao quadro do paciente e acessível ao médico veterinário, para que se possa alcançar sucesso na recuperação do paciente. Assim, mesmo o flap de terceira pálpebra não sendo o método de eleição para tratamento de úlceras de córnea colagenolítica em cães, conforme a literatura consultada, a técnica mostrou-se extremamente satisfatória e aplicável ao caso. 


\section{CONCLUSÃO}

Pôde-se concluir que o flap simples de terceira pálpebra, com fixação palpebral, aliado ao tratamento tópico com colírios antibiótico, cicloplégico e inibidor de protease, foi eficaz para tratamento de úlcera de córnea colagenolítica difusa em cão.

\section{REFERÊNCIAS}

BOJRAB, M. J. Técnicas Atuais em Cirurgia de Pequenos Animais. 3.ed. São Paulo: Roca, 1996. 896 p.

BRITO, F. L. C.; CUNHA, O.; LAUS, J. L. Limbal autograft transplantation in a dog with alkali-induced ulceration. Ciência Rural, Santa Maria, v. 40, p. 1840-1843, 2010.

CAMPOS, C. F.; JORGE, A. T.; TALIERI, I. C.; VICENTI, F. A. M.; TOLEDO-PIZA, E.; LAUS, J. L. Ocular alkali lesions in dogs. Acetylcysteine and blood serum effects. Brazilian Journal of Veterinary Research and Animal Science [online], v. 40, n. 1. p. 36-44, 2003. Disponível em: http://www.scielo.br/scielo.php?script=sci_arttext\&pid=S1413-

95962003000100004\&Ing=en\&nrm=iso\&tIng=en. Acesso em: 21 dez. 2013.

CHOW, D. W. Y.; WESTERMEYER, H. D. Retrospective evaluation of corneal reconstruction using $\mathrm{ACellVet}^{\mathrm{TM}}$ alone in dogs and cats: 82 cases. Veterinary Ophthalmology [on line], p. 1-10, 2015. Disponível em: http://onlinelibrary.wiley.com/doi/10.1111/vop.12294/abstract. Acesso em: 31 ago. 2015.

DUBIELZIG, R. R.; KETRING, K.; McLELLAN, G. J.; ALBERT, D. M. Veterinary Ocular Pathology: a comparative review. Philadelphia: Saunders Co., 2010, 453p.

DULAURENT, T.; AZOULAY, T.; GOULLE, F.; DULAURENT, A.; MENTEK, M.; PEIFFER, R. L.; ISISARD, P. F. Use of bovine pericardium (Tutopatch@) graft for surgical repair of deep melting corneal ulcers in dogs and corneal sequestra in cats. Veterinary Ophthalmology [online], v. 17, n. 2, p. 91-99, 2014. Disponível em: http://www.ncbi.nlm.nih.gov/pubmed/23621151. Acesso em: 31 ago. 2015.

ESCARIÃO, A. C. S. L.; RIBEIRO, E. S.; JORGE, P. A.; LEITE, E. C. S.; BRANDT, C. T. Efeito terapêutico do crosslinking corneal na ceratite infecciosa. Revista Brasileira de Oftalmologia, Rio de Janeiro, v. 72, n. 6, p. 366-372, nov./dez. 2013.

FAMOSE, F. Evaluation of accelerated collagencross-linking for the treatment of melting keratitis in eight dogs. Veterinary Ophthalmology [on line], v. 17, n. 5, p. 358-367, 2014. Disponível em: http://www.ncbi.nlm.nih.gov/pubmed/23902524. Acesso em: 31 ago. 2015.

GALERA, P. D.; MUNGER, R. J.; LAUS J. L. Ulcerative keratitis and keratomalacia in a dog caused by papain: a case report. Revista Brasileira de Ciência Veterinária [online], v. 11, n. 1/2, p. 113-115, jan./ago. 2004. Disponível em: http://doi.editoracubo.com.br/10.4322/rbcv.2014.356. Acesso em: 02 set. 2015. 
GALERA, P.D.; LAUS, J.L.; ORIÁ, A.P. Afecções da túnica fibrosa. In: LAUS, J. L. Oftalmologia Clínica e Cirúrgica em Cães e em Gatos. São Paulo: Roca, p. 69-96, 2009.

GELATT, K.N.; BROOKS, D. Surgery of the córnea and sclera. In: GELATT, K.N.; GELATT, J.P. Veterinary Ophthalmic Surgery. Gainesville: Saunders Elsevier. P. 191-235, 2011a.

GELATT, K.N.; BROOKS, D. Surgical procedures for de conjunctiva and the nictitating membrane. In: GELATT, K.N.; GELATT, J.P. Veterinary Ophthalmic Surgery. Gainesville: Saunders Elsevier. P. 157-190, 2011b.

GILGER, B. C.; OLLIVIER F. J.; BENTLEY E. Diseases and surgery of the canine cornea and sclera. In: GELATT, K. N. Veterinary Ophthalmology. 5.ed. lowa: Wiley-Blackwell, p. 690-752, 2013.

GOULLE, F. Use of porcine small intestinal submucosa for corneal reconstructionin dogs and cats: 106 cases. Journal of Small Animal Practice online, jan. 2012, v. 53, p. 34-43. Disponível em: http://www.ncbi.nlm.nih.gov/pubmed/22122191. Acesso em : 01 set. 2015.

HERRERA, D. Oftalmologia Clínica em Animais de Companhia. São Paulo: MedVet, 2008. $300 \mathrm{p}$.

KEALY, J. K.; McALLISTER, H. Radiologia e Ultra-sonografia do Cão e do Gato. 3.ed. Barueri: Manole, 2005. 436 p.

KIM, J. K.; WON, H.; JEONG, S. A retrospective study of ulcerative keratitis in 32 dogs. The International Journal of Applied Research in Veterinary Medicine [online], v. $7, \quad$ n. $1 . \quad$ p. 27-31, 2009. Disponível em: http://www.jarvm.com/articles/Vol7lss1n2/ulcer.pdf. Acesso em: 26 dez. 2013.

MAGGS, D. J. Cornea and sclera. In: MAGGS, D. J; MILLER, P.; OFRI, R. Slatter's Fundamentals of Veterinary Ophthalmology. 5.ed., Rio de Janeiro: Saunders Elsevier, p. 175-202, 2013.

MARTINS, B.C.; RIBEIRO, A.P.; LAUS, J.L.; ORTIZ, J.P.D. Glaucoma. In: LAUS, J. L. Oftalmologia Clínica e Cirúrgica em Cães e em Gatos. São Paulo: Roca, p. 151-167, 2009.

MILLER, P.E. Uvea. Slatter's Fundamentals of Veterinary Ophthalmology. 5.ed., Rio de Janeiro: Saunders Elsevier, p. 175-202, 2013.

OLLIVIER, F. J.; GILGER, B. C.; BARRIE, K. P.; KALLBERG, M. E.; PLUMMER, C. E.; O'REILLY, S.; GELATT, K. N.; BROOKS, D.E. Proteinases of the cornea and preocular tear film. Veterinary Ophthalmology [online], v. 10, p. 199-206, 2007. Disponível em: http://www.ncbi.nlm.nih.gov/pubmed/17565550. Acesso em 01 set. 2015.

PONTES, K. C. S.; BORGES, A. P. B.; ELEOTÉRIO, R. B.; FAVARATO, L. S. C.; DUARTE, T. S. Processo de reparação de lesões da córnea e a membrana 
amniótica na oftalmologia. Ciência Rural, Santa Maria, v. 41, n. 12, p. 2120-2127, 2011.

POT, S. A.; GALLH $\square$ FER, N. S.; MATHEIS, F. L.; VOELTER-RATSON, K.; HAFEZI, F.; SPIESS, B. M. Corneal collagen cross-linking as treatment for infectious and noninfectious corneal melting in cats and dogs: results of a prospective, nonrandomized, controlled trial. Veterinary Ophthalmology [on line], v. 17, n. 4, p. 250-260, 2014. Disponível em: http://www.ncbi.nlm.nih.gov/pubmed/23941330. Acesso em : 02 set. 2015.

PUMPHREY, S. A.; PIZZIRANI, S.; PIRIE, C. G. 360-degree conjunctival grafting for management of diffuse keratomalacia in a dog. Veterinary Ophthalmology [online], v. $14, \quad$ n. $3, \quad$ p. 209-213, 2011. Disponível em: http://onlinelibrary.wiley.com/doi/10.1111/j.1463-5224.2010.00864.x/full. Acesso em: 31 ago. 2015.

SAMPAIO, G. R. Oftalmologia: doenças corneanas em pequenos animais. Lavras: UFLA/FAEPE, 2007. 136 p.

SPIESS, B. M.; POT, S. A.; FLORIN, M.; HAFEZI, F. Corneal collagen cross-linking $(\mathrm{CXL})$ for the treatment of melting keratitis in cats and dogs: a pilot study. Veterinary Ophthalmology [on line], v. 17, n. 1, p. 1-11, 2014. Disponível em: http://www.ncbi.nlm.nih.gov/pubmed/23356663. Acesso em : 02 set. 2015.

TUDURY, E. A.; POTIER, G. M. A. Tratado de Técnica Cirúrgica Veterinária. São Paulo: MedVet, 2009. 447 p.

TURNER, S. M. Oftalmologia em Pequenos Animais. Rio de Janeiro: Elsevier, 2010. $370 \mathrm{p}$.

VIANA, F.A.B.; FULGENCIO, G.O.; BORGES, K.D.A. Farmacologia oftalmológica. In: SPINOSA, H.S.; GÓRNIAK, S.L.; BERNARDI, M.M. Farmacologia Aplicada à Medicina Veterinária. Rio de Janeiro: Guanabara Koogan. 5 ed. P. 705-715, 2011.

VONGSAKUL, S.; TUNTIVANICH, P.; SIRIVAIDYAPONG, S.; KALPRAVIDH, M. Canine amniotic membrane transplantation for ocular surface reconstruction of created deep corneal ulcers in dogs. Thai Journal of Veterinary Medicine, Bangkok, v. 39, n. 2. p. 135-144, 2009. 